\title{
Use of antibiotics at the emergency department
}

\author{
Line Damsgaard*, Asta Oestergaard \\ From Danish Society for Emergency Medicine: Research Symposium 2010 \\ Roskilde, Denmark. 20-21 May 2010
}

\section{Background}

The question about rational use of antibiotics is always topical. The aim of the present research was to analyse the use of antibiotics in an emergency department (ED):

Which antibiotics are prescribed, how often and under which diagnoses? Are they appropriate and are they changed in the stationary unit? (All admitted patients are transferred to other units after initial treatment in the ED). Finally, which microbial cultures are performed before initiation of antibiotic treatment?

\section{Methods}

Retrospective analysis of 865 records on admitted patients and 1100 notes on ambulant patients from the ED at Køge Hospital, from October to December 2009. Doctors were not informed beforehand about the subsequent analysis.

To evaluate the choice of antibiotic we used the national recommendations (www.medicin.dk). If any doubt, we used the regional department of microbiology at Slagelse Hospital as reference.

\section{Results}

Antibiotics were prescribed to $9 \%$ of admitted patients. Main diagnoses were pneumonia (39\%), septicaemia/ sepsis $(20 \%)$ and urinary tract infections (UTI's) (14\%). The most frequently used antibiotics were cefuroxim and benzylpenicillin intravenously (alone or in combination with other antibiotics).

$3 \%$ of ambulant patients received antibiotics, mainly because of infected or potentially infected skin lesions (91\%). Most received tablets of phenoxymethylpenicillin, and the doses varied considerably.

In $100 \%$ of skin infections, $90 \%$ of pneumonia cases, $75 \%$ of septicaemia/sepsis cases and $36 \%$ of UTI's the choice of antibiotics was in accordance with national recommendations.

\footnotetext{
* Correspondence: linedams@gmail.com

Emergency Department, Copenhagen University Hospital in Køge, Denmark
}

Sputum culture was made in $7 \%$ of pneumonia cases, urine cultures in $60 \%$ of cases with UTI's. Blood cultures were generally performed with a high frequency.

48 hour follow up showed that in $81 \%$ of cases, treatment was not substantially changed in the stationary unit.

\section{Conclusion}

Focus on appropriate microbial cultures and correct choice and doses of antibiotics needs to be increased. Treatment of UTI's has to be reconsidered, as use of cefuroxim was high among these patients. Cefalosporins select ESBL-producing bacteria, and their use needs to be reduced to a minimum. Specific local guidelines for the management of infected patients are in progress, and after implementation of these we will perform a new analysis to assess the effect.

Published: 17 September 2010

doi:10.1186/1757-7241-18-S1-P39

Cite this article as: Damsgaard and Oestergaard: Use of antibiotics at the emergency department. Scandinavian Journal of Trauma, Resuscitation and Emergency Medicine 2010 18(Suppl 1):P39.

\section{Submit your next manuscript to BioMed Central and take full advantage of: \\ - Convenient online submission \\ - Thorough peer review \\ - No space constraints or color figure charges \\ - Immediate publication on acceptance \\ - Inclusion in PubMed, CAS, Scopus and Google Scholar \\ - Research which is freely available for redistribution \\ Submit your manuscript at www.biomedcentral.com/submit}

